\title{
COMO ACOLHER AS DIFERENTES MANIFESTAÇÕES CULTURAIS NA EDUCAÇÃO INFANTIL?
}

HOW TO APPROACH THE DIFFERENT CULTURAL MANIFESTATIONS IN PRESCHOOL EDUCATION?

\author{
Raquel Dilly Konrath'
}

\author{
Recebido em: 03 de dezembro de 2016 \\ Aprovado em: 03 de abril de 2017 \\ Sistema de Avaliação: Double Blind Review \\ RCO | a. 9 | v. 2 | p. 16-25 | jul./dez. 2017
}

\begin{abstract}
RESUMO
Este trabalho tem como objetivo trazer algumas reflexões teóricas por meio de uma revisão bibliográfica, acerca da importância do contexto educativo da Educação Infantil como um espaço e lugar de reconhecimento às diferentes manifestações culturais, e que seja construído com e pelo grupo que ali vive e convive, sendo também a sua base e a sua própria expressão. Nessa visão, rompe-se com a ideia de condicionamento passivo da criança em relação à cultura do adulto e passa-se a concebê-la como participante ativa da construção de um mundo social. As reflexões apresentadas terão como referência princial a base teórica, os estudos de Jane Hislan, Manuel Jacinto Sarmento, Gilles Brougère e Audrey Curtis, entre outros, abordando o brincar em diferentes culturas e a produção de pedagogias interculturais na infância. Para que as diferentes manifestações culturais das crianças sejam acolhidas na Educação Infantil, de modo que sejam respeitadas e incorporadas na prática, faz-se necessário que a atitude de aceitação do outro, em suas diferenças e particularidades, também esteja presente na postura de vida dos adultos com quem convivem na instituição. Os brinquedos, como suportes da brincadeira, podem apresentar-se como um importante artefato cultural, que não apenas traduzem uma visão de mundo, mas que se tornam uma importante possibilidade para acolher a diversidade cultural presente numa Escola de Educação Infantil, deixando que a criança expresse a sua cultura e conheça outras. E que, por meio de diferentes linguagens, possa traduzir a sua forma de ser criança, bem como conhecer muitas outras novas formas de pensar, ver e agir e viver a sua infância.
\end{abstract}

Palavras-chave: Manifestações culturais. Educação Infantil. Crianças. Brinquedos.

\begin{abstract}
This paper aims at bringing up some theoretical reflections, through a bibliographic review, about the importance of the educative context in Preschool Education as a space and place of recognition to the different cultural manifestations which is built by and with the group who lives and interacts there, also being its basis and its own expression. Through this vision, the idea of passive child conditioning towards the adult cultural world is broken and the child starts to be seen as an active participant of the social world construction. The reflections presented will have as theoretical basis the studies of Jane Hislan, Manuel Jacinto Sarmento, Gilles Brougère and Audrey Curtis, among others, approaching the act of playing in different cultures as well as the production of intercultural pedagogies in the childhood. So that the different cultural manifestations may be approached in Preschool Education in order that they get respected and included into praxis, it is necessary that the attitude of acceptance by other people, in their differences and particularities, is also presented in the adults' lives who live with these children. The toy, as a support for the plays, may be introduced as an important cultural artifact, which not only translates a view of the world, but also becomes an important possibility to approach the cultural diversity ,present in a Preschool environment, allowing the child to express his own culture while
\end{abstract}

\footnotetext{
${ }^{1}$ Mestre em Teologia pela Escola Superior de Teologia (São Leopoldo/Brasil). Professora do Instituto Superior de Educação Ivoti (Ivoti/Brasil). E-mail: raqueldilly@ terra.com.br.
} 
meeting others and, through different kinds of languages, may translate its own way of being a child as wells as getting to know many other different ways of thinking, seeing, acting and living his childhood. Keywords: Cultural Manifestations. Education. Childhood. Toys.

\section{INTRODUÇÃO}

De que forma acontece o acolhimento às diferentes expressões e manifestações das crianças nas escolas de Educação Infantil? Acontece? De que forma o brinquedo pode ser considerado um aliado na expressividade da criança? Esses e outros questionamentos vêm se intensificando em pautas de formação de educadores, em estudos e pesquisas acadêmicas, tanto quanto em diferentes referências oficiais e marcos legais nacionais, de forma que já formamos certo consenso, ao menos no nível do discurso, no que se refere à inserção das diferentes expressões e manifestações culturais na proposta curricular da Educação Infantil. Isso significa que ninguém mais duvida ou questiona a importância de reconhecermos e valorizarmos as diferentes manifestações culturais nas práticas pedagógicas educativas, principalmente por meio do brincar. Mas, ao analisarmos as diferentes formas pelas quais as manifestações culturais são inseridas e reconhecidas, ainda encontramos muitas diferenciações, tensões e contradições, tanto em relação às intenções quanto às vivências e práticas no cotidiano infantil.

Percebemos que as práticas sociais e culturais das próprias crianças nem sempre são consideradas nas experiências e vivências pedagógicas nos contextos da educação infantil. $\mathrm{O}$ que prevalece geralmente é o conhecimento e a cultura do adulto.

Seria possível pensarmos em acolhimento das diferentes culturas, valores e crenças na Escola Infantil sem ouvir e/ou considerar o grupo de crianças que a constitui? Que crianças constituem a nossa escola, o nosso grupo? O que e como pensam? O que e como sentem? Acolher e inserir as diferentes manifestações e expressões culturais na educação infantil requer pensar numa escola como um espaço e um lugar que seja construído com e pelo grupo que ali vive, sendo também a sua base e a sua própria expressão.

Para refletir, neste estudo e pesquisa, sobre a importância do acolhimento das diferentes manifestações culturais das crianças na Educação Infantil, foram utilizados como principais bases de referência e análise os fundamentos teóricos de Manuel Jacinto Sarmento (2007) e Gilles Brougère (2001), que sustentam a ideia de que para investigar as crianças de um contexto, organização ou instituição é preciso estudá-las a partir de si próprias e não de generalizações, modelos universalizantes ou padrões sociais dos adultos e as conceberem como importantes atores sociais, produtoras e (re)construturas de cultura, e não meras reprodutoras. A pesquisa ainda se fundamenta nos pressupostos teóricos de Audrey Curtis (2006) e Jane Hislan (2006), que apresentam os brinquedos e as brincadeiras como artefatos e expressões culturais e importantes possibilidades de acolhimento às diferentes manifestações culturais das crianças.

Esta pesquisa de cunho bibliográfica qualitativa fundamenta-se em explorar e aprofundar alguns conceitos e atributos sobre o acolhimento às diferentes manifestações culturais das crianças na Educação Infantil e sobre a importância das brincadeiras e brinquedos na mediação desse processo.

Refletir, portanto, sobre o acolhimento das diferentes culturas no contexto escolar infantil sob essa perspectiva requer olharmos e refletirmos também sobre a cultura escolar que ainda predomina na proposta curricular da educação infantil. 


\section{AS DIFERENTES MANIFESTAÇÕES CULTURAIS NO CONTEXTO DA EDUCAÇÃO INFANTIL}

Quando a gente cresce um pouco É coisa de louco o que fazem com a gente: Tem hora pra levantar, hora pra se deitar, Pra visitar parente.

Quando se aprende a falar, se começa a estudar, Isso não acaba nunca. E só vai saber ler, só vai saber escrever Quem aprender o bê-a-bá. (TOQUINHO, 2016).

É essa Educação Infantil que queremos para as nossas crianças? Como organizamos os tempos e os espaços na Educação Infantil considerando as manifestações e as expressões culturais das próprias crianças e das famílias que habitam esse lugar? Como a escola de Educação Infantil vem considerando a infância nas suas diferentes possibilidades? Esses questionamentos são necessários, se nos propusermos a inserir a diversidade cultural no espaço educativo infantil, pois não podemos mais conceber uma única organização curricular escolar e uma padronização de rotinas infantis, como se todas as crianças fossem iguais em suas necessidades, capacidades, interesses, possibilidades, crenças e valores. Tudo isso requer reconhecer a instituição e as crianças "em seu caráter não homogêneo, avistando as diferenças de maneira a tornar visível a pluralidade cultural ali existente" (MARTINS FILHO, 2015, p. 21).

Inserir, portanto, as diferentes manifestações culturais na Educação Infantil significam considerar a diversidade de etnias, crenças e costumes, valores que marcam a vida das crianças e suas famílias em cada contexto. Além disso, é preciso considerar tudo isso na organização curricular, enquanto proposta educativa, bem como na organização do tempo e do espaço físico e nas próprias relações estabelecidas e vivenciadas na instituição.

Isso sugere um desvelamento das manifestações que são próprias do universo cultural infantil e a desconstrução e relativização de algumas certezas e verdades que já tivemos ou ainda temos em relação à educação das crianças. Então:

Sustenta-se a necessidade de se rever as posturas das investigações sobre as crianças, propondo-se a um olhar que as considere como sujeitos empíricos, com voz, vez e expressões próprias. Por esse enfoque, é possível ver as crianças a partir de suas experiências e manifestações, principalmente aquelas construídas por meio das relações estabelecidas com seus pares e não mais como sujeitos passivos, ainda que elas sejam interdependentes dos adultos ou de outros grupos sociais, como, por exemplo, a família, os contextos institucionais de educação e o Estado (MARTINS FILHO, 2015, p. 9).

As Diretrizes Curriculares Nacionais da Educação Infantil (BRASIL, 2010, p. 12) apresentam a criança como:

Sujeito histórico e de direitos que, nas interações, relações e práticas cotidianas que vivencia, constrói sua identidade pessoal e coletiva, brinca, imagina, fantasia, deseja, aprende, observa, experimenta, narra, questiona e constrói sentidos sobre a natureza e a sociedade, produzindo cultura.

Ao considerar a criança como sujeito histórico, que constrói sua identidade pessoal e social nas relações e práticas cotidianas que vivencia e estabelece com o meio, as Diretrizes Curriculares também 
reconhecem a importância da interação entre a escola e as famílias das crianças, uma vez que a criança compartilha os dois contextos. Isto significa que a escola de Educação Infantil deve procurar:

Compreender o que acontece com as famílias, entender seus valores ligados a procedimentos disciplinares, a hábitos de higiene, a forma de se relacionar com as pessoas etc. pode auxiliar a construção conjunta das ações. De maneira geral, as instituições de educação devem servir de apoio real e efetivo às crianças e suas famílias, respondendo às suas demandas e necessidades. Evitar julgamentos moralistas, pessoais ou vinculados a preconceitos é condição para o estabelecimento de uma base para o diálogo (BRASIL, 1998, p. 77-78).

Esta compreensão implica uma construção conjunta de ações, em que a Escola de Educação Infantil deve acolher e respeitar as demandas e necessidades das crianças e suas famílias. E não em que crianças e famílias são obrigadas a adaptar-se a uma organização curricular rígida, estabelecida ou imposta pela Instituição sem considerar as diferenças daqueles que a compõem. Outro aspecto importante a ser considerado é de que "cada família é portadora de um vasto repertório que se constitui em material rico e farto para o exercício do diálogo" (BRASIL, 1998, p. 77). Mas para isso faz-se necessário o desenvolvimento e a capacidade de ouvir, observar e aprender com as famílias.

Ao reconhecermos a importância da comunicação e do diálogo com as crianças e de suas famílias na construção conjunta de ações na Educação Infantil, parece-nos claro de que não nos é mais possível enquadrar a criança na mesma organização curricular de tempo e espaço, como já vínhamos fazendo há muito tempo atrás. Essa concepção implica numa organização curricular construída e vivenciada a partir de oportunidades variadas, incluindo as manifestações das crianças e das famílias que constituem cada grupo e instituição escolar.

Nesse contexto, buscamos compreender as crianças para além de simples seres paralisados, homogêneos, engessados e enquadrados numa lógica anestesiada de controle e vigia que venha a interditar momentos de descoberta, privando a criança de viver a diversidade cultural e a expressão das diferenças (MARTINS FILHO, 2015, p. 19).

Para isso, faz-se necessário acolher as experiências e as vivências das próprias crianças, rejeitando a ideia de que existe apenas um modo e uma forma de ser criança e viver a infância. Ou ainda, acolher, respeitar e valorizar a pluralidade cultural, sem que isso signifique ou implique a adesão incondicional aos valores do outro. Faz-se necessário vivenciar a pluralidade cultural nas relações cotidianas, praticála por meio da convivência diária.

Acolher as diferentes culturas não pode se limitar às comemorações festivas, a eventuais apresentações de danças típicas ou à experimentação de pratos regionais. Estas iniciativas são interessantes e desejáveis, mas não são suficientes para lidar com a diversidade de valores e crenças (BRASIL, 1998, p. 77).

Para lidar com a diversidade de valores e crenças, faz-se necessário criar situações e condições que favoreçam a identidade e a manifestação cultural, aproveitando e significando as práticas cotidianas das famílias e das crianças na organização do espaço e do tempo. No entanto: 
É fundamental pensar em práticas específicas para cada criança. Mesmo apresentando algumas características comuns nos grupos culturais, uma é diferente da outra, o que requer observá-las individualmente, para que os interesses e as necessidades de cada uma façam parte do planejamento curricular. Não apenas na sua entrada na creche, mas a qualquer momento, em todos os dias, o cuidado com a individualidade e a diversidade aumentam as oportunidades de educação.

Nessa perspectiva, abre-se a necessidade de diferentes tempos e espaços de escuta para que os diferentes sujeitos da Instituição possam se manifestar, se expressar e se sentirem pertencentes. Segundo Barthes (2013, p. 331), o poder exercido pela linguagem, seja verbal ou não verbal, tem como utopia diminuir as diferenças entre os sujeitos, para constituir a ideia do "viver junto". Nesse contexto, é preciso considerar a Cultura como uma escuta das forças e das diferenças. Para Barthes (2013, p. 11), o "viverjunto" é também temporal, que significa viver ao mesmo tempo em que viver no mesmo tempo. A partir desse entendimento, é pertinente incluir a compreensão que temos em relação a essa escuta, considerando as diferentes formas de expressão e de manifestação que podemos considerar em se tratar de uma Escola de Educação Infantil, em que o tempo do "viver junto" é uma constante muito intensa. No entanto, Barthes (2013, p. 289) argumenta que: "de qualquer maneira, não existem máquinas de ler, de escutar os sentidos". Isso significa que mesmo abrindo diferentes tempos e espaços para que as crianças e famílias se manifestem e expressem a sua cultura, esta escuta ainda pode ser intuitiva e subjetiva, pois será interpretada e explicada a partir da construção e produção do sistema de significados daquele que as recebe e as acolhe, e que podem não representar o mesmo sentido de quem as produz. Para isso, precisamos desafiar as suposições:

Como adultos, nós raramente olhamos as coisas com uma mente inteiramente aberta e podemos não perceber por que silenciamos aspectos significativos e ignoramos outros. As nossas preconcepções fazem diferença na nossa maneira de ver as coisas. Em certa extensão, vemos e ouvimos o que queremos ver e ouvir. Portanto, o que pensamos e esperamos precisa estar sob constante exame e nós devemos questionar as nossas suposições, e também aquilo que lemos e ouvimos, examinando atentamente as evidências de que dispomos (HISLAM, 2006, p. 57).

Mesmo que a escuta se faça a partir de interpretações subjetivas e intuitivas, ainda pode ser um importante caminho para respeitarmos as individualidades e as diferentes manifestações culturais, não procurando homogeneizar, por meio de rituais e rotinas fixas e estáveis, padrões de comportamento, atitudes e aprendizagens das crianças e de suas famílias, sendo talvez também um importante indício para a construção da "utopia do viver junto".

\section{O BRINQUEDO COMO UMA POSSIBILIDADE DE ACOLHER AS DIFERENTES MANIFESTAÇÕES CULTURAIS DAS CRIANÇAS}

A criança não sabe senão viver a sua infância.

Conhecê-la pertence ao adulto. Mas o que vai prevalecer neste conhecimento: o ponto de vista do adulto ou da criança? (WALLON, 1989, p.9)

As crianças são diferentes, constroem sua identidade própria, pois vivem em famílias distintas, provêm de comunidades étnicas, raciais, culturais, religiosas e níveis econômicos diversos. Como podemos aproveitar essa diversidade cultural utilizando os brinquedos?

No que diz respeito à diversidade de manifestações e expressões culturais, é importante destacar o investimento e o incremento, pelo menos nas últimas décadas, de ações em prol de uma proposta 
curricular que reconheça a importância dos brinquedos na educação infantil como uma forma da própria criança manifestar a sua cultura e conhecer novas, tanto em contextos formais e não formais de educação. Cabe, portanto, uma reflexão acerca das práticas pedagógicas dentro das escolas, ou seja, de que forma estas permitem que as manifestações e expressões culturais das próprias crianças sejam vivenciadas como experiências no cotidiano ou que sejam simplesmente trabalhadas como conteúdo e atividades de forma isolada.

A brincadeira e a seleção de brinquedos são hoje consideradas temas relevantes e fundamentais a serem pesquisados e inseridos nas práticas pedagógicas escolares, pois são compreendidos como uma expressão da cultura e não apenas afetados por influências culturais. Isso significa, conforme Curtis (2006, p. 39), que "a nossa percepção do brincar está estreitamente associada às nossas crenças e valores sociais". Por exemplo, nossas preferências, assim como as das crianças, por certos tipos de brincadeiras e de brinquedos, estão relacionadas ao contexto social e cultural. Nessa compreensão, faz-se necessário reconhecer a importância do brincar e a seleção dos brinquedos como elementos fundamentais para acolher e valorizar as diferentes manifestações culturais, principalmente as manifestadas pelas próprias crianças dentro de cada instituição educativa.

Um dos importantes investimentos feitos nos últimos anos pelo Ministério de Educação Básica foi a publicação de um documento técnico: Brinquedos e Brincadeiras nas Creches - Manual de Orientação pedagógica (BRASIL, 2012), elaborado para orientar professores, educadores e gestores, esclarecendo que os brinquedos e a brincadeira são constitutivos da infância. Segundo este Manual (BRASIL, 2012), a introdução de brinquedos e brincadeiras na Educação Infantil depende de condições prévias, e que estas condições requerem o detalhamento de aspectos que emergem na prática pedagógica. E aborda como um destes aspectos a necessidade da seleção dos brinquedos, contemplando os interesses e necessidades das crianças de diferentes segmentos étnicos, sociais e culturais.

Outro importante Referencial para a Educação Infantil é a Base Nacional Curricular Comum (BNCC) (BRASIL, 2016), elaborada com o objetivo de garantir direitos de aprendizagem a todas as crianças do país e a serem implantados em cinco campos de experiência. Nessa abordagem a BNCC apresenta, em seu texto preliminar, como um dos seis direitos de aprendizagem, o "Brincar", e, como suporte deste brincar, a disponibilização de indumentárias, acessórios, objetos cotidianos associados a diferentes papéis ou cenas sociais. Ainda coloca, como outro direito de aprendizagem, "Conviver democraticamente, com outras crianças e adultos, com eles interagir, utilizando diferentes linguagens, e ampliar o conhecimento e o respeito em relação à natureza, à cultura, às singularidades e às diferenças entre as pessoas".

Os Referenciais Nacionais, assim como tantos outros, apresentam os brinquedos, considerados e significados nestes documentos como suporte da brincadeira, como fundamentais para a convivência com os outros e a expressão dos movimentos e dos gestos que marcam a cultura da criança. E como forma de valorizar as diferenças individuais e coletivas existentes em seu contexto escolar, aprendendo a respeitar as diferentes identidades e culturas.

A autora e pesquisadora Adriana Friedmann (2012) também enfatiza que a atividade lúdica é uma ótima oportunidade para conhecer as crianças, "conhecer os valores, as ideias, os interesses e as necessidades", apontando como caminho a observação do brincar espontâneo. Apresenta-o como "livre e prazeroso", em que a própria criança define como, quando, com o que brincar, com quem e durante o tempo que desejar. Essa prática nem sempre é compreendida desta forma pelos educadores, pois muitos ainda a concebem como um intervalo entre uma atividade e outra, sem a necessidade do 
acompanhamento, observação e registro, desconsiderando esse momento como uma experiência e oportunidade importante para a criança se expressar autonomamente e espontaneamente.

O brincar espontâneo abre a possibilidade de observar escutar as crianças nas suas linguagens mais expressivas mais autênticas. A observação das crianças enquanto brincam e o registro das características das brincadeiras permitem fazer uma leitura do grupo (FRIEDMANN, 2012, p. 47).

Proporcionar momentos e espaços para o brincar espontâneo infantil torna-se uma importante e significativa forma de acolher e valorizar a diversidade cultural das próprias crianças. A observação e o registro da origem histórica e antropológica da brincadeira, assim como recorrer à memória e a relatos de pessoas que fazem parte do universo da criança, também são imprescindíveis para fazer uma leitura do grupo. Outro aspecto que pode ser observado e registrado são os brinquedos e materiais utilizados como suporte da brincadeira, assim como as regras utilizadas para o desenvolvimento da brincadeira. A ressignificação das regras e as variações das brincadeiras também são aspectos importantes a serem observados e registrados, evitando neste sentido a padronização de modelos e formas impostas pela cultura do adulto ou da escola.

Curtis (2006, p. 41) reforça essa ideia afirmando que "os efeitos do ambiente familiar não podem ser ignorados, pois têm considerável influência sobre os padrões posteriores do comportamento do brincar da criança." Isso evidencia a importância do acolhimento às diferenças, expressas de forma espontânea e autônoma pela criança por meio da brincadeira e do brinquedo, fator que às vezes ainda é ignorado pela escola.

O brinquedo também se evidencia como uma possibilidade de acolher diferentes culturas, bem como de favorecer a expressividade espontânea e autêntica da criança, pois nele existem diferenças culturais interessantes referentes a valores atribuídos e relacionados a diferentes padrões estéticos, significados e/ou interesses. Nesse sentido, faz-se necessário refletir sobre a variedade, a diversidade e a multiplicidade de brinquedos que disponibilizamos às nossas crianças, uma vez que agimos como modelos para as crianças, ao atribuirmos implicitamente nossos valores a certos tipos de brinquedos e não a outros. Isso pode acontecer quando limitamos as oportunidades de brincadeiras com certos brinquedos.

As crianças certamente são influenciadas e captam essas atitudes dos professores, sejam elas exibidas em nível consciente ou inconsciente. [...] Isso pode ter um efeito sutil e prejudicial sobre a autoimagem das crianças, de modo que alguns padrões de brincar são inibidos e pode, de fato, deixar de ocorrer (HISLAM, 2006, p. 60-62).

Nas lojas de brinquedos, alguns estereótipos culturais em relação a gênero, a padrões de beleza, assim como outros, são reforçados de forma rígida e cruel. As pressões comerciais são intensas e sedutoras, mas se quisermos de fato acolher, valorizar e respeitar as diferentes culturas, precisamos rever as nossas atitudes e posturas frente às escolhas e à seleção dos brinquedos que oferecemos e disponibilizamos para as nossas crianças na escola.

Daí a necessidade de nos questionarmos sobre a relação entre o brinquedo hoje produzido, selecionado e disponibilizado para as crianças e a construção da sua identidade, assim como pensarmos sobre como vêm se modificando a forma de ser criança e a sua cultura lúdica ao longo dos tempos e quais os efeitos dessa produção cultural.

De acordo com Dornelles e Bujes (2012, p. 80): “a criança carrega consigo uma cultura, concebida simbolicamente na imersão das vivências experimentadas em sua comunidade, da qual fará uso ao longo 
de sua vida." No entanto, Sarmento (2007, p. 36) nos fala "que as crianças incorporam, interpretam e reconstroem continuamente informações culturais, constituídas por valores, normas sociais, ideias, crenças e representações (que fazem parte) dos artefatos culturais." Isso nos faz pensar que a criança, mesmo estando exposta a certos estereótipos culturais, vai construindo a sua cultura de forma individual a partir de suas significações, com um modo de pensar próprio. Brougére (2001, p. 32) nos diz que "quem brinca se serve de elementos culturais heterogêneos para construir sua própria cultura lúdica com significações individualizadas, atribuindo sentido e significado aos brinquedos e às brincadeiras.

A literatura que fundamenta esse campo reflete uma mudança gradual em sua ênfase, que se afasta das ideias de condicionamento passivo e se aproxima de uma visão das crianças como participantes ativos da construção de um mundo social (HISLAM, 2006, p.51).

Assim, desconstruímos a ideia e o argumento de que os brinquedos são fatores determinantes da visão ideológica das crianças e não a concebemos como produtora, ou (re)criadora de cultura, mas uma mera reprodutora. Hislam (2006, p. 51) contribui, reforçando o papel ativo da criança: "Nós precisamos abandonar a ideia de que as crianças absorvem estereótipos criados e passar a vê-las como seres que elaboram as suas próprias conclusões sobre o que é apropriado e aceitável".

Nessa visão a importância dos brinquedos evidencia-se pelo fato da própria criança poder construir, interpretar e reconstruir continuamente informações culturais, constituídas por valores, normas sociais, ideias, crenças e representações presentes nestes artefatos culturais (SARMENTO, 2007). Mas, para que a criança possa se expressar, utilizando diferentes brinquedos, é necessário que se criem situações e condições em que espontaneamente com outras crianças e adultos, utilizando diferentes materiais, ela vivencie a diversidade de possibilidades e manifestações culturais, superando as rotinas fixas e engessadas e as visões discriminatórias e cheias de preconceito em relação a estereótipos, ainda muito presentes na cultura escolar. E, assim, a criança vai se constituindo, ou seja, constituindo sua forma de ser e de se produzir como sujeito hoje.

\section{CONSIDERAÇÕES FINAIS}

A pesquisa bibliográfica realizada mostrou ser possível constatar que o acolhimento às diferentes manifestações culturais das crianças, tomadas e consideradas fundamentais hoje em diferentes estudos e em todas as referências legais nacionais da Educação Infantil, não pode ser apenas naturalizado e assumido como discurso de consenso como se todas as Instituições educativas fossem iguais, sem considerar o próprio contexto, ou seja, as manifestações e as expressões culturais das próprias crianças, suas famílias e os diferentes profissionais que habitam cada lugar ou compõem a comunidade escolar.

Para que as diferentes manifestações culturais das crianças sejam acolhidas na Educação Infantil, de modo que sejam respeitadas e incorporadas na prática, faz-se necessário que a atitude de aceitação do outro, em suas diferenças e particularidades, também esteja presente na postura de vida dos adultos com quem convivem na instituição. E, em se tratando de posturas de vida, assumidas e tomadas por diferentes sistemas de significados, não existe homogeneização e/ou consenso no que se refere ao acolhimento e respeito às diferentes manifestações culturais. Mesmo havendo importantes Referências Nacionais legais e pedagógicas que orientam e normatizam a prática pedagógica da Educação Infantil, favorecendo a identidade e a diversidade cultural. As Referências e documentos Nacionais são importantes, mas são apenas políticas públicas traduzidas em palavras, e qualquer texto, num outro 
contexto, tem sentidos e significados diferentes, pois cada contexto educativo ou cada profissional interpreta, traduzindo a sua visão de mundo, tornando cada leitura uma nova leitura.

A partir desta pesquisa e estudo foi possível constatar que os brinquedos, como suportes da brincadeira, podem apresentar-se como uma importante possibilidade de acolher a diversidade cultural presente numa Escola de Educação Infantil, pois favorecem a expressividade espontânea e autêntica da criança, uma vez que apresentam e contém diferenças culturais interessantes referentes a valores atribuídos e relacionados a diferentes padrões estéticos, significados e/ou interesses. A importância dos brinquedos evidencia-se pelo fato da própria criança poder construir, interpretar e reconstruir continuamente informações culturais, constituídas por valores, normas sociais, ideias, crenças e representações presentes nestes artefatos culturais.

Assim, o acolhimento às diferentes manifestações culturais das crianças na Educação Infantil pode de fato acontecer desde que a criança possa expressar a sua cultura e tenha a oportunidade de conhecer outras, e que, por meio de diferentes oportunidades de exploração de brinquedos e linguagens, possa traduzir a sua visão de mundo e a sua forma de ser criança, bem como conhecer muitas outras novas formas de pensar e agir.

\section{REFERÊNCIAS}

BARTHES, R. Como viver junto: simulações romanescas de alguns espaços cotidianos. 2. ed. São Paulo: Editora WMF Martins Fontes, 2013.

BRASIL. Secretaria de Educação Fundamental. Referencial Curricular Nacional para a Educação Infantil. Volume 2: formação pessoal e social. Brasília: MEC/SEF, 1998.

. Secretaria de Educação Básica. Diretrizes curriculares nacionais para a educação infantil. Brasília: MEC/SEB, 2010.

Secretaria de Educação Básica. Brinquedos e brincadeiras nas creches: manual de orientação pedagógica. Ministério da Educação. Brasília: MEC/SEB, 2012.

. Ministério da Educação. Base Nacional Comum Curricular. 2. ed. rev. Brasília: MEC, 2016. Disponível em: <http://basenacionalcomum.mec.gov.br/documento/BNCCAPRESENTACAO.pdf>. Acesso em: 28 nov. 2015.

BROUGÈRE, G. A criança e a cultura lúdica. In: KISCHIMOTO, Tizuko Morchida (Org.). O brincar e as suas teorias. São Paulo: Pioneira Thomson Learning, 2001. p. 19-32.

CURTIS, A. O brincar em diferentes culturas e em diferentes infâncias. . In: MOYLES, Janete. R. et al. A excelência do brincar: A importância da brincadeira na transição entre a educação infantil e anos iniciais. Porto Alegre: Artmed, 2006. p.39-49.

DORNELLES, L. V; BUJES, M. I. E. Educação e infância na era da informação. Porto Alegre: Mediação, 2012. p.103-130.

FRIEDMANN, A. O brincar na educação infantil: observação, adequação e inclusão. São Paulo: Moderna, 2012.

HISLAM, J. Experiências do brincar diferenciadas pelo sexo e pelas escolhas das crianças. In: MOYLES, Janete. R. et al. A excelência do brincar: a importância da brincadeira na transição entre a educação infantil e anos iniciais. Porto Alegre: Artmed, 2006. p. 50-62. 
MARTINS FILHO, A. J (Org.). Criança pede respeito: ação educativa na creche e pré-escola. Porto Alegre: Mediação: 2015.

SARMENTO, M. J. Produzindo pedagogias interculturais na infância. Petrópolis: Vozes, 2007.

TOQUINHO. Bê-A-Bá. Vagalume. Disponível em: <https://www.vagalume.com.br/toquinho/be-aba.html>. Acesso em: 02 dez. 2015.

WALLON, H. As origens do pensamento na criança. São Paulo: Manole, 1989. 